\title{
Immune Benefits of Consuming Red Muscadine Wine ${ }^{1}$
}

\author{
Susan S. Percival, Charles A. Sims, and Stephen T. Talcott ${ }^{2}$
}

\section{Overview}

Wine, and especially red wine, contains compounds that have promising health benefits. Red wine has more potential benefits than white wine or grape juice because of the specific phytochemical compounds found in grape skins that are extracted during fermentation.

Phytochemicals are naturally occurring substances found in fruits and vegetables that have some type of biologic activity. One class of phytochemicals, phenolic compounds, is especially prevalent in grape skins. Phenolic compounds act as antioxidants-substances that neutralize free radicals produced by our

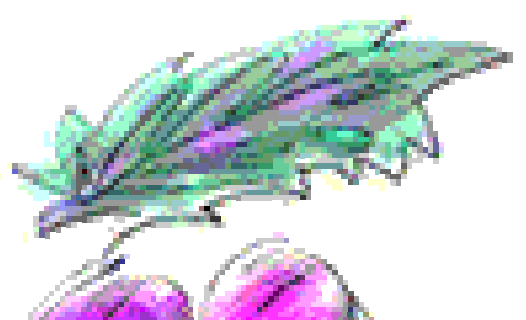
normal metabolism. Free radicals are unstable molecules that react rapidly with other molecules leading to cellular damage by oxidation. This damage has been linked to signs of aging, cancer, heart disease, stroke, degeneration of the eye, and other disease processes. Alcohol consumption may cause production of free radicals during its detoxification process in the liver, but the phytochemicals in red wine, and their antioxidant activity may counteract the effects of alcohol detoxification.

\section{Wine is the "...healthiest and most health-giving of drinks." --Louis Pasteur}

1. This document is FSHN02-4, one of a series of the Food Science and Human Nutrition Department, Florida Cooperative Extension Service, Institute of Food and Agricultural Sciences, University of Florida. Publication: September 2002. Reviewed by: R.E. Turner, Ph.D., associate professor; and D.L. Archer, Ph.D., professor, both of the Food Science and Human Nutrition Department, Cooperative Extension Service, Institute of Food and Agricultural Sciences, University of Florida, Gainesville, FL 32611-0370.

2. S.S. Percival, Ph.D., professor; C.A. Sims, Ph.D., professor; and S.T. Talcott, Ph.D., assistant professor, all of the Food Science and Human Nutrition Department, Cooperative Extension Service, Institute of Food and Agricultural Sciences, University of Florida, Gainesville, FL 32611-0370. title, Food Science and Human Nutrition Department, Cooperative Extension Service, Institute of Food and Agricultural Sciences, University of Florida, Gainesville, FL 32611-0370. 
Our research focuses on the muscadine grape species (Vitis rotundifolia) and suggests that there is a greater potential for health benefits from red muscadine wine than from other red grape species. Muscadine grapes (both domesticated and wild) are native to the Southeast region of the United States and have been enjoyed for over 250 years. They have been shown to be rich in total phenolic compounds, ellagic acid, and catechins (Tables 1 and 2).

Table 1. Comparison of Phenolic Compounds in Muscadine and Cabernet Sauvignon Wines. Source: Auw, Blanco, O'Keefe and Sims, $1996^{1}$

\begin{tabular}{|l|c|c|}
\hline Mg/Liter & Muscadine Wine (HP) & $\begin{array}{c}\text { Cabernet Sauvignon Wine } \\
\text { (HP) }\end{array}$ \\
\hline Total Phenols & 834 & 534 \\
\hline Gallic acid & 14 & 3 \\
\hline Ellagic acid & 8 & None detected \\
\hline Catechin & 5 & 11 \\
\hline Epicatechin & 22 & 2 \\
\hline B3 procyanidin & 0.3 & 25 \\
\hline
\end{tabular}

Table 2. Effect of Processing and Fermentation Time on Phenolic Compounds of Muscadine and Cabernet Sauvignon Wines. Source: Auw, Blanco, O'Keefe and Sims, $1996^{1}$

\begin{tabular}{|l|l|l|c|c|c|c|}
\hline Grape & Compound & $\begin{array}{c}\text { Immediate } \\
\text { press }\end{array}$ & $\begin{array}{c}\text { Hot } \\
\text { press }\end{array}$ & $\begin{array}{c}\text { 1-3 day skin } \\
\text { fermentation }\end{array}$ & $\begin{array}{c}\text { 7 day skin } \\
\text { fermentation }\end{array}$ & $\begin{array}{c}\text { 14 day skin } \\
\text { fermentation }\end{array}$ \\
\hline \multirow{3}{*}{ Muscadine } & Ellagic acid & 0.5 & 8 & 3 & 6 & 4 \\
\cline { 2 - 8 } & Gallic acid & 4 & 14 & 45 & 148 & 200 \\
\hline & $\begin{array}{l}\text { Catechin + } \\
\text { epicatechin }\end{array}$ & 3 & 30 & 40 & 120 & 205 \\
\hline \multirow{2}{*}{ Cabernet } & Gallic acid & 2 & 3 & 7 & 16 & 16 \\
\hline & $\begin{array}{l}\text { Catechin + } \\
\text { epicatechin }\end{array}$ & 8 & 13 & 60 & 73 & 110 \\
\hline
\end{tabular}

Table 3. Effect of Processing and Fermentation Time on Phenolic Compounds in Muscadine Wine Source: Talcott and Lee $\mathrm{Le}^{3}, 2002$

\begin{tabular}{|l|c|c|c|c|}
\hline Compound & Cold Press & $\begin{array}{c}\text { Hot press } \\
\text { 3 day skin } \\
\text { fermentation }\end{array}$ & $\begin{array}{c}\text { Hot press } \\
\text { 5 day skin } \\
\text { fermentation }\end{array}$ & $\begin{array}{c}\text { Hot press } \\
\text { 7day skin } \\
\text { fermentation }\end{array}$ \\
\hline Ellagic acid & 3 & 56 & 54 & 53 \\
\hline Quercetin & 1.5 & 40 & 37 & 34 \\
\hline Total Phenolics & 403 & 1600 & 1840 & 1860 \\
\hline
\end{tabular}

Depending on the type of processing, muscadine wine may contain 3-4 times more phenolic compounds than wine made from California red wine grapes (Vitis vinifera). Ellagic acid, a known anti-cancer compound, is found in appreciable amounts in muscadine wine, but not in Cabernet wine for example (Tables 1 and 3). Quercetin is a potent antioxidant compound found in significant quantities many fruits and vegetables including muscadine wine and other red wines as well.

We investigated the health benefits of wine on the immune system in an animal model. If alcohol detoxification creates free radicals, we expected to see unfavorable effects on the immune system. Mice consumed a red muscadine wine ( $V$. rotundifolia, phenolic content $1731 \mathrm{mg} / \mathrm{L})$, a cabernet sauvignon $(V$. vinifera, phenolic content $912 \mathrm{mg} / \mathrm{L}$ ), ethanol (all at $6 \%$ alcohol), or water for 8 weeks. At the end of this time, we made half of the mice mildly ill with an injection of lipopolysaccharide (LPS), a compound derived from bacteria. The amount of wine consumed by the mice was equivalent to two and one-half glasses of wine by an adult human, based on calories consumed. This is a moderate intake. 
Our first observation was that mice consuming either of the wines had significantly greater plasma total antioxidant levels than mice consuming water or ethanol (Figure 1). This indicates that antioxidant protective activity can accumulate in the blood with moderate amounts of wine. The normal response to an injection of LPS is a higher plasma antioxidant capacity due to the release of the production of acute phase reactants in the blood. Notice in Figure 1 that the animals that consumed straight ethanol were not able to raise their antioxidant levels significantly.

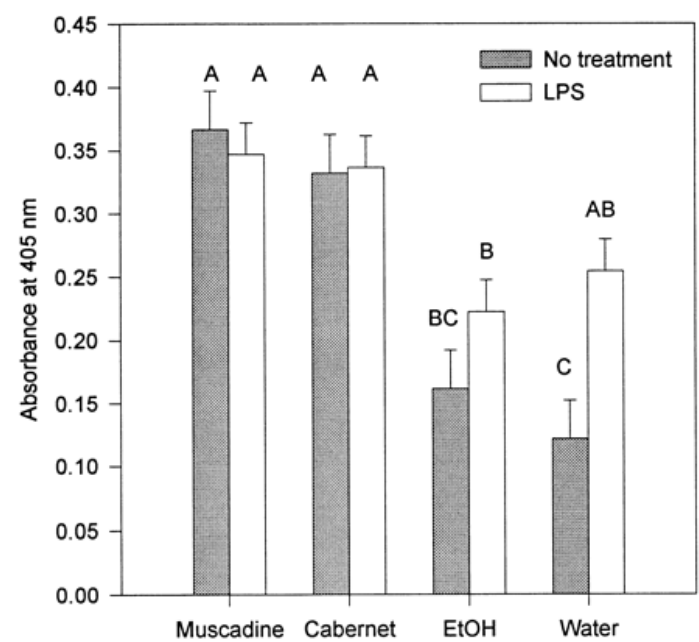

Figure 1. Total antioxidant capacity of plasma of mice con suming red wines, ethanol or water for 8 wk with and without lipopolysaccharide (LPS) stimulation. Values represent the means $\pm S D, n=4$ in the group without treatment and $n=6$ in the lipopolysaccharide-stimulated group. Bars with different letters are significantly different at $P<0.05$. Source: Percival SS, Sims CA. Wine modifies the effects of alcohol on immune cells of mice. J.Nutr. 2000;130:1091-1094.

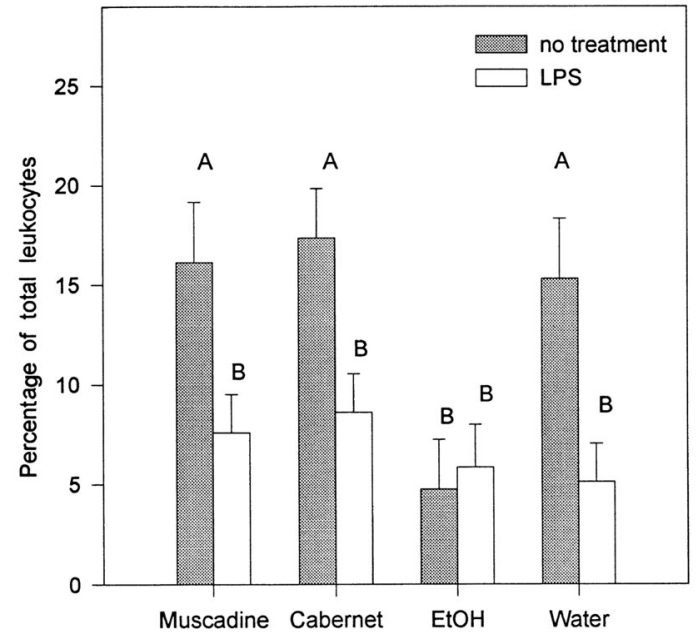

Figure 2. T Lymphocytes as a percentage of total leukocytes in mice consuming red wines, ethanol, or water for $8 \mathrm{wk}$ with and without lipopolysaccharide (LPS) stimulation. Values represent the means \pm $\mathrm{SD},=4$ in the group without treatment and $n=6$ in the LPSstimulated group. Bars having different letters are significantly different at $P<0.05$. Source: Percival SS, Sims CA. Wine modifies the effects of alcohol on immune cells of mice. J.Nutr. 2000;130:1091-1094.

T lymphocytes are a type of white blood cell important to immunity and host protection. During an immune response, $\mathrm{T}$ cells migrate out of the blood into the lymph system. As shown in Figure 2, baseline levels of $T$ cells in the animals that consumed ethanol were lower than the control animals or in either of the wine-drinking animals. When stimulated with LPS, the T cell levels stayed the same in the ethanol-drinking group compared to before LPS, suggesting that the cells did not migrate out as expected. Thus, ethanol had a detrimental effect on this aspect of immunity. Our results clearly show that when the same amount of ethanol is consumed in the form of wine, the immune system responded appropriately.

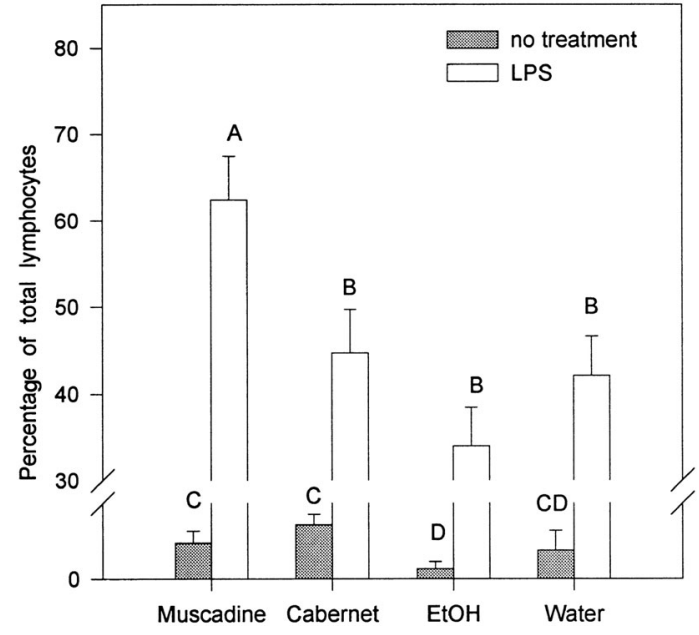

Figure 3. Natural killer cells as a percentage of total lymphocytes in mice consuming red wines, ethanol, or water for $8 \mathrm{wk}$ with and without lipopolysaccharide (LPS) stimulation. Values represent the means \pm $\mathrm{SD}, \mathrm{n}=4$ in the group without treatment and $\mathrm{n}=6$ in the LPSstimulated group. Bars having different letters are significantly different at $P<0.05$.. Source: Percival SS, Sims CA. Wine modifies the effects of alcohol on immune cells of mice. J.Nutr. 2000;130:1091-1094.

Natural killer (NK) cells are a type of lethal lymphocyte that combat tumor cells and infected cells in the body. Similar to T cells, the number of NK cells present in the blood was lower in the ethanol-consuming animals compared to the animals that consumed the same amount of ethanol in the form of wine and the animals that consumed water (Figure 3). 
The normal response to LPS is an increased appearance of NK in the blood. Consumption of muscadine wine resulted in a significant increase in number of NK cells in the blood compared to the control and the cabernet-consuming animals. While muscadine grapes have a unique phenolic profile compared to the cabernet, the component that is responsible for the higher proportion of NK cells after LPS stimulation is still unknown.

Finally, specific alcohol detoxification enzymes in liver were measured (data not shown). Changes occurred in the levels of Phase 1 and Phase 2 enzymes that were interpreted as protective. Muscadine wine differed from the Cabernet, which was interpreted as more protective. From this study, we concluded that red wine contains compounds that offset the detrimental effects of ethanol. Wine consumption increased antioxidant activity in the blood and did not result in lower T lymphocytes and NK cells in the blood.

This research is further discussed on these websites, as well as others.

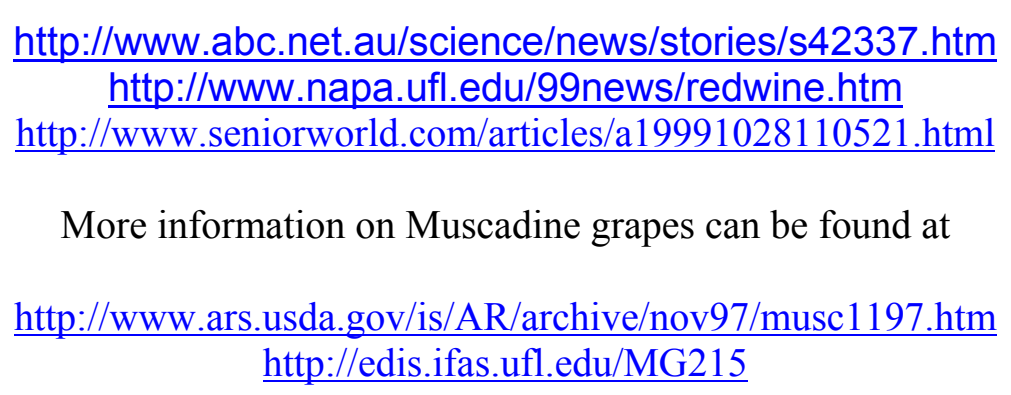

\section{References}

1. Auw J, Blanco V, O'Keefe S, Sims CA. Effect of processing on the phenolics and color of Cabernet Sauvignon, Chambourcin, and Noble wines and juices. Am.J.Enol.Vitic. 1996;47:279-286.

2. Percival SS, Sims CA. Wine modifies the effects of alcohol on immune cells of mice. J.Nutr. 2000;130:1091-1094.

3. Talcott, S.T. and Lee, J-H. Ellagic acid and flavonoid antioxidant content of muscadine wine and juice J. Agric. Food Chem. 2002, 50: 3186-3192. 